www.jmscr.igmpublication.org

Index Copernicus Value: 79.54

ISSN (e)-2347-176x ISSN (p) 2455-0450

crossrefDOI: https://dx.doi.org/10.18535/jmscr/v7i2.176

\title{
Comparison of Post Cesarean Analgesia with Epidural Bupivacaine- Fentanyl v/s Bupivacaine-Nalbuphine v/s Bupivacaine-Butorphanol - A Double Blinded Randomized Study
}

Authors

A Karthik ${ }^{1}$, Satish Logidasan ${ }^{2}$, Arulraj G.P ${ }^{3}$, R Kanimozhi ${ }^{4}$, A Gowri Shankar ${ }^{5}$, S Prasana Vathanan', Ambal $\mathrm{S}^{7}$, C Sathish ${ }^{8}$

Corresponding Author

S.R. Karthick

Department of Anesthesiology, Govt Stanley Medical College, TN- 600001, India

Email: Karthicksr_kmcbq@yahoo.com

\begin{abstract}
80 ASA physical status I and II women, aged 20-30 years, undergoing Elective Cesarean Section were included in the study. Patients were randomly allocated to four groups during the postoperative period to receive one of four epidural regimens: Group 1(NS): $10 \mathrm{ml}$ of 0.125\% Bupivacaine $+1 \mathrm{ml}$ of Normal Saline; Group 2(FENT) $10 \mathrm{ml}$ of 0.125\% Bupivacaine + 50ug of Fentanyl (1ml); Group 3(NALB) 10ml of 0.125\% Bupivacaine $+5 \mathrm{mg}$ of Nalbuphine $(0.5 \mathrm{ml})+0.5 \mathrm{ml}$ of Normal saline to make it into $1 \mathrm{ml}$; Group 4 (BUTOR): $10 \mathrm{ml}$ of $0.125 \%$ Bupivacaine $+1 \mathrm{mg}$ of Butorphanol $(1 \mathrm{ml})$.

Onset and duration of analgesia were recorded. Hemodynamic variables, pain scores, sedation scores, and respiratory rate were monitored for 24 hours. Frequency and severity of respiratory depression, sedation, pruritus, nausea, and vomiting were recorded. The mean onset of analgesia and times to reach peak analgesia were significantly shorter while the mean durations of analgesia were significantly longer in the groups receiving fentanyl, nalbuphine \& butorphanol than in the group receiving bupivacaine alone. The onset of analgesia was earliest with Butorphanol group. The duration of analgesia was maximum with Butorphanol group. None of the patients developed hypotension, Bradycardia, respiratory depression.

Epidural 0.125\% Bupivacaine combined with Butorphanol produces significantly earlier onset, longer duration and better quality of analgesia than 0.125\% Bupivacaine - Nalbuphine combination / $0.125 \%$ Bupivacaine -Fentanyl combination / 0.125\% Bupivacaine alone and is safe in parturients.
\end{abstract}

\section{Introduction}

The perioperative period is associated with a variety of pathophysiologic responses that may be initiated or maintained by nociceptive input. Although these responses may have had a beneficial teleologic purpose, the same response to the iatrogenic nature of modern-day surgery may be harmful. Uncontrolled perioperative pain may potentiate some of these perioperative pathophysiologies and increase patient morbidity and mortality. Hence Postoperative pain relief is very essential in improving perioperative care $\&$ hence quality of health care given to the patient.

The concept of opiate receptor subtypes (mu1 \& mu2, kappa and sigma) and the advent of drugs with receptor-specific agonist and antagonist properties 
have further expanded the role of epidural opioids for intraoperative, postoperative, and obstetrical uses. Such opioids in combination with Local Anaesthetics are not only valuable in providing good analgesia, but also prolongs the duration of analgesia. Fentanyl, a synthetic opioid is a pure mu receptor agonist, and is highly lipid soluble. The mu receptor agonism leads to various side effects such as respiratory depression, nausea, vomiting, reduced GI motility, sedation \& physical dependence. Hence the need of opioids with lesser side effects, but with good analgesic properties, led us to consider opioids agonist-antagonist - Butorphanol \& Nalbuphine as additives to local anaesthetic (via epidural route) for postcesarean analgesia.

\section{Aim of the Study}

Comparison and study of post cesarean analgesia and side effect profile of epidural $0.125 \%$ bupivacaine-fentanyl v/s $0.125 \%$ bupivacainenalbuphine v/s $0.125 \%$ bupivacaine - butorphanol.

\section{Methodology}

After getting Ethical committee approval, 80 parturients belonging to ASA physical status I \& II undergoing Elective LSCS were enrolled.

\section{Inclusion Criteria}

ASA Class I \& II

Elective cesarean section

\section{Exclusion Criteria}

ASA Class III \& IV (Severe PIH, Stenotic Valvular Heart disease) Emergency Surgery (Includes Fetal distress, threatened rupture, hemodynamic compromise).

Not willing for Epidural

Psychiatric patients

Bleeding diathesis

H/o. hypersensitivity to Opioid /LA

In the preanaesthetic visit, all the patients were made familiar with the study plan. Respiratory rate, Non invasive blood pressure, peripheral arterial saturation and heart rate were monitored throughout the perioperative period. Patients were monitored with pulse oximetry, NIBP \& ECG. Respiratory rate also was recorded.
Intravenous Hydration with $12-15 \mathrm{ml} / \mathrm{kg}$ of fluid prior to surgery. Epidural Catheter is placed in L2L3 or L3-L4 interspace. Approximately $4 \mathrm{~cm}$ of catheter was kept inside the space. A test dose of $2 \mathrm{ml}$ of $0.5 \%$ Bupivacaine was given via catheter before it is fixed. After confirming the epidural placement of the catheter, incremental doses of $0.5 \%$ Bupivacaine $(5 \mathrm{cc})$ was given until a bilateral T6 sensoroy level (determined by pin prick) was attained. Till the incision time parturient was placed in operating table in a left lateral tilt. Oxygen at $4 \mathrm{~L} / \mathrm{min}$ via venturi mask was provided. If there was any hypotension (MAP $<60 \mathrm{~mm} \mathrm{Hg}$ ) Inj. Ephedrine $6 \mathrm{mg}$ iv was given along with intravenous fluid. If the Heart rate fell below 50/mt, Inj Atropine 0.6mg iv was given.

Epidural route was used for surgery \& postoperative analgesia. If the epidural block failed, regional anaesthesia was converted to General Anaesthesia and the parturient was excluded from the study. Opioid was not administered during the intraoperative period. After the surgery was over parturients were shifted to labour ward postoperative recovery room.

The parturients were observed for pain on a $10 \mathrm{~cm}$ VAS. When the epidural effect of local anaesthetic given in the intraoperative period was wearing off \& when they complained of pain (VAS of $5 \mathrm{~cm}$ ), they were classed into four groups randomly as follows \& study drugs were given epidurally for the respective groups.

Group 1 (NS): 20 parturients receiving 10ml of $0.125 \%$ Bupivacaine $+1 \mathrm{ml}$ of Normal Saline (Total $=11 \mathrm{ml})$

Group 2 (FENT): 20 parturients receiving 10ml of $0.125 \%$ Bupivacaine $+50 u g$ of Fentanyl $(1 \mathrm{ml})$ $($ Total $=11 \mathrm{ml})$

Group 3 (NALB): 20 parturients receiving $10 \mathrm{ml}$ of $0.125 \%$ Bupivacaine $+5 \mathrm{mg}$ of Nalbuphine $(0.5 \mathrm{ml})$ $+0.5 \mathrm{ml}$ of Normal saline to make it into $1 \mathrm{ml}$ (Total $=11 \mathrm{ml}$ )

Group 4 (BUTOR): 20 parturients receiving 10ml of $0.125 \%$ Bupivacaine $+1 \mathrm{mg}$ of Butorphanol (1ml) $($ Total $=11 \mathrm{ml})$ 
Pain score was observed at $2 \mathrm{~min}, 4 \mathrm{~min}, 6 \mathrm{~min}, 8 \mathrm{~min}$, $10 \mathrm{~min}, 15 \mathrm{~min}, 20 \mathrm{~min}, 25 \mathrm{~min}, 30 \mathrm{~min} \&$ then every $1 / 2$ hourly intervals upto $10 \mathrm{hrs}$ on a $10 \mathrm{~cm}$ VAS ('no pain' at $0 \mathrm{~cm}$ end and 'worst pain ever' at $10 \mathrm{~cm}$ end). The observer assessing pain was kept blinded for the epidural medication. Thereafter, continuous measurement of pain by VAS was made at intervals till the patient was completely free of pain (VAS 0). If the VAS score failed to decline atleast by $1 \mathrm{~cm}$ even after $30 \mathrm{~min}$ of epidural injection, the patient was given intramuscular diclofenac sodium $75 \mathrm{mg}$ and was excluded from the study.

The onset of analgesia was defined as the time from injection of the study medication to first reduction in pain intensity by at least $1 \mathrm{~cm}$ in VAS; the onset of peak analgesia was defined as the time to achieve the lowest VAS score; and the duration of analgesia was defined as the time between the onset of analgesia and either a return to baseline VAS of $5 \mathrm{~cm}$ (after which patients were given i.m diclofenac $\&$ study concluded). If any patient demanded pain relief before the study could be completed they were also given i.m diclofenac \& were excluded from the study. The quality of analgesia was assessed based on the overall satisfaction of the patient and the time of the first changing of positions side to side independently in the bed. The overall satisfaction of the patient was assessed with a $10 \mathrm{~cm}$ scale of VAS Satisfaction ('no satisfaction' at $0 \mathrm{~cm}$ end and 'the best satisfaction' at $10 \mathrm{~cm}$ end). Motor block if any was assessed using the Bromage Score.

Sedation was assessed when the VAS score reached the minimum (using Modified Ramsay sedation score). The occurrence of nausea and vomiting, pruritus and respiratory depression (respiratory rate $<10 /$ min) was noted up to 24 hours following administration of the study medication.

The collected data was analyzed statistically: Analysis of variances (ANOVA) was used for comparison of mean values between more than two groups; Posthoc test was used to find any significance between the individual groups, Chi square test was used to compare the discrete variables between groups. A $\mathrm{p}$ value of $<0.05$ was considered significant.

\section{Scales \& Scores Used}

\section{Visual Analogue Scale}

"Please make a mark on this line that describes how much pain you are having"
No pain
0 $1 \_2 \_3 \_4 \quad 5 \quad 6$ $7 \_8$ 10 Worst imaginable pain

\section{Patient Satisfaction Scale}

\begin{tabular}{|c|c|c|c|c|c|c|c|c|c|c|}
\hline $\begin{array}{c}\text { Completely } \\
\text { Dissatisfied } \\
0\end{array}$ & 1 & 2 & 3 & 4 & 5 & 6 & 7 & 8 & 9 & $\begin{array}{l}\text { Completely } \\
\text { Satisfied } \\
10\end{array}$ \\
\hline & & & & & & & & & & \\
\hline
\end{tabular}

\section{Bromage Scale}

\begin{tabular}{|l|c|c|}
\hline Grade & Criteria & Degree of block \\
\hline I & $\begin{array}{c}\text { Free movement of legs and } \\
\text { feet }\end{array}$ & Nil (0\%) \\
\hline II & $\begin{array}{c}\text { Just able to flex knees with } \\
\text { free movement of feet }\end{array}$ & Partial (33\%) \\
\hline III & $\begin{array}{c}\text { Unable to flex knees, but } \\
\text { with free movement of feet }\end{array}$ & Almost complete (66\%) \\
\hline IV & $\begin{array}{c}\text { Unable to move legs or } \\
\text { feet }\end{array}$ & Complete (100\%) \\
\hline
\end{tabular}

\section{Modified Ramsey Sedation Scale}

1. anxious and agitated or restless, or both

2. co-operative, oriented, and calm

3. responsive to commands only

4. exhibiting brisk response to light glabellar tap or loud auditory stimulus

5. exhibiting a sluggish response to light glabellar tap or loud auditory stimulus

6. unresponsive 


\section{Nausea / vomiting}

0 - No nausea/vomiting

1- Nausea

2- Vomiting

0 - No pruritus

1- Pruritus

\section{Independent change of position}

Patient able to change position side to side freely -1

Not able to change position because of pain/discomfort -0

Bradycardia $\mathrm{HR}<50 / \mathrm{min}$

0 - No Bradycardia

1- Presence of Bradycardia

Respiratory depression

$\mathrm{RR}<10 / \mathrm{mt}$

0 - No Respiratory depression

1 - Presence of Respiratory depression

Desaturation: SPO2 <95\%

0 - No desaturation

1 - Presence of desaturation

Hypotension

Systolic BP $<80 \mathrm{~mm} \mathrm{Hg}$

MAP $<60 \mathrm{~mm} \mathrm{Hg}$

\section{Results}

The data of only 77 patients were included for calculation because three patients were dropped from the study as they had patchy sensory blockade to an extent of converting to GA.

Mean onsets of analgesia and times to reach peak analgesia were significantly shorter while the mean durations of analgesia were significantly longer in the groups receiving fentanyl, nalbuphine \& butorphanol than in the group receiving bupivacaine alone. Also there is a statistical significance between individual groups. The onset of analgesia was earliest with Butorphanol group followed by fentanyl group, Nalbuphine group \& finally by control group. The onset of peak analgesia occurred first in the Butorphanol group followed by fentanyl group, Nalbuphine group \& finally by control group The duration of analgesia was maximum with Butorphanol group (mean of $360 \mathrm{~min}$ approx), followed by Fentanyl group (mean of $279 \mathrm{~min}$ approx), Nalbuphine group (mean of $246 \mathrm{~min}$ approx) \& control group (mean of 212min approx).

Table - 1

\begin{tabular}{|l|c|c|c|c|}
\hline $\begin{array}{l}\text { Parameter } \\
(\mathbf{m i n})\end{array}$ & $\begin{array}{c}\text { Group } \\
\text { NS } \\
(\mathbf{n = 1 8})\end{array}$ & $\begin{array}{c}\text { Group } \\
\text { FENT } \\
(\mathbf{n = 2 0})\end{array}$ & $\begin{array}{c}\text { Group } \\
\text { NALB } \\
(\mathbf{n = 1 9 )}\end{array}$ & $\begin{array}{c}\text { Group } \\
\text { BUTOR } \\
(\mathbf{n = 1 9 )}\end{array}$ \\
\hline $\begin{array}{l}\text { Onset of } \\
\text { analgesia }\end{array}$ & 8.22 & 4.20 & 5.42 & 3.42 \\
\hline $\begin{array}{l}\text { Peak onset of } \\
\text { analgesia }\end{array}$ & 21.39 & 8.65 & 10.16 & 8.42 \\
\hline $\begin{array}{l}\text { Duration of } \\
\text { analgesia }\end{array}$ & 211.94 & 279.20 & 245.53 & 360.11 \\
\hline
\end{tabular}

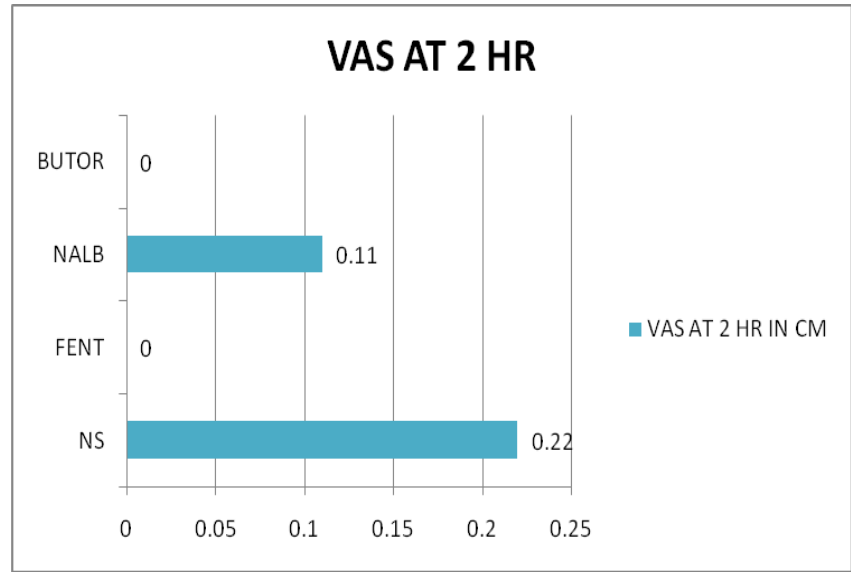

Fig - 1

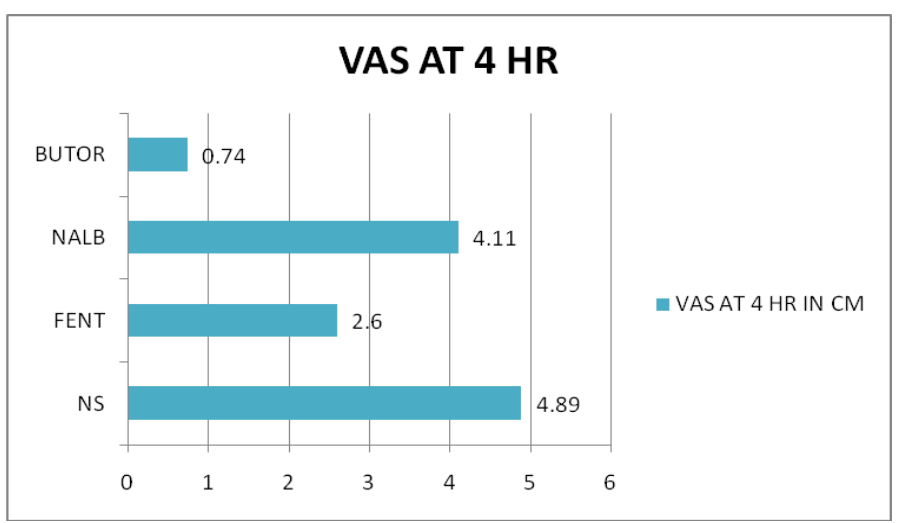

Fig -2 


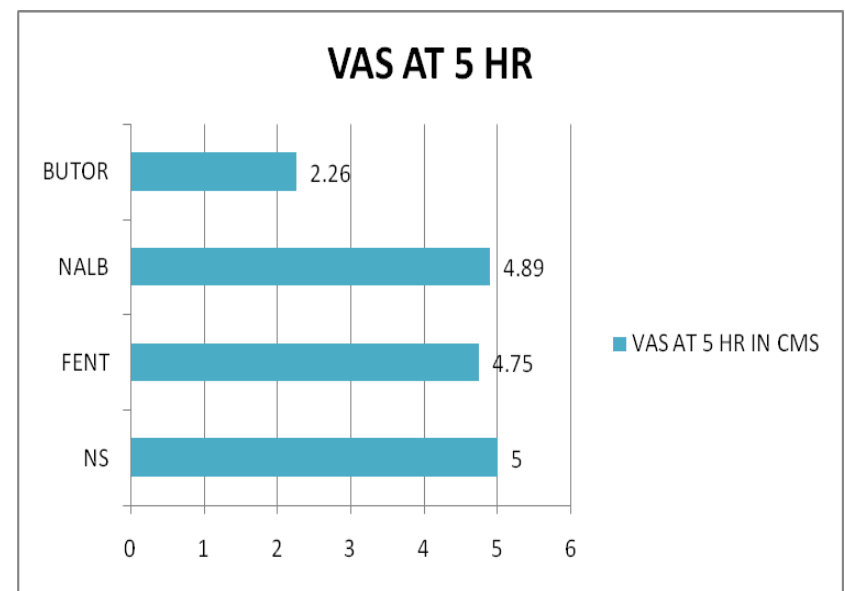

Fig -3

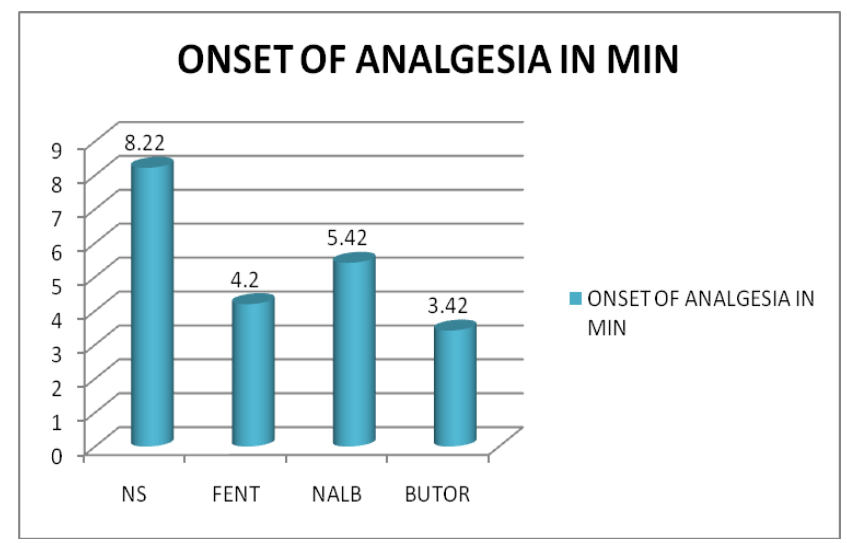

Fig - 4

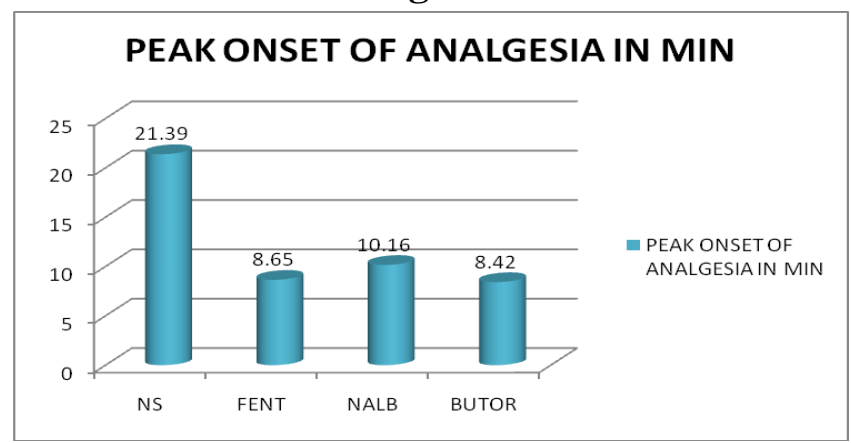

Fig - 5

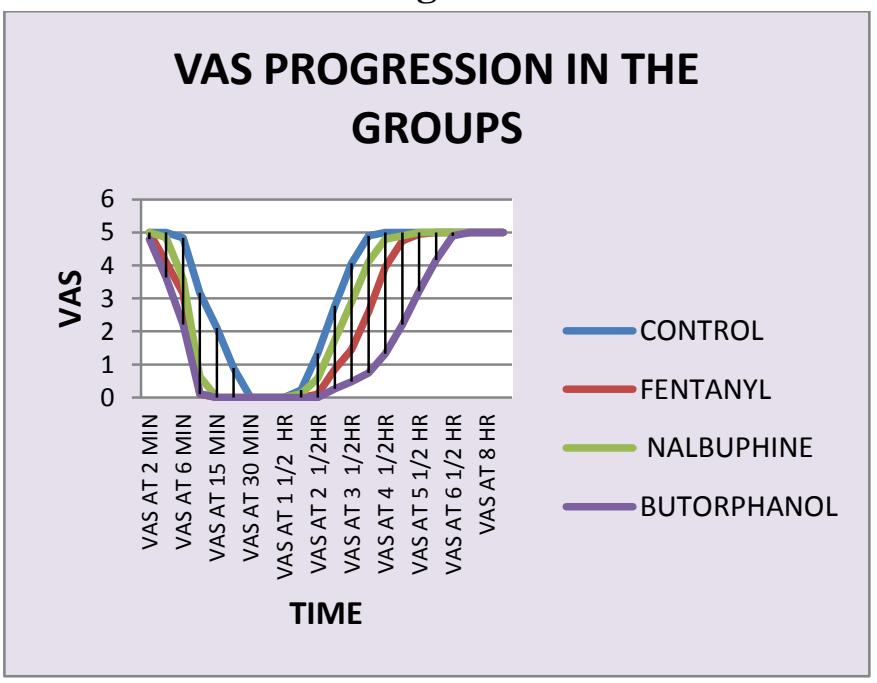

Fig -6

\section{DURATION OF ANALGESIA}

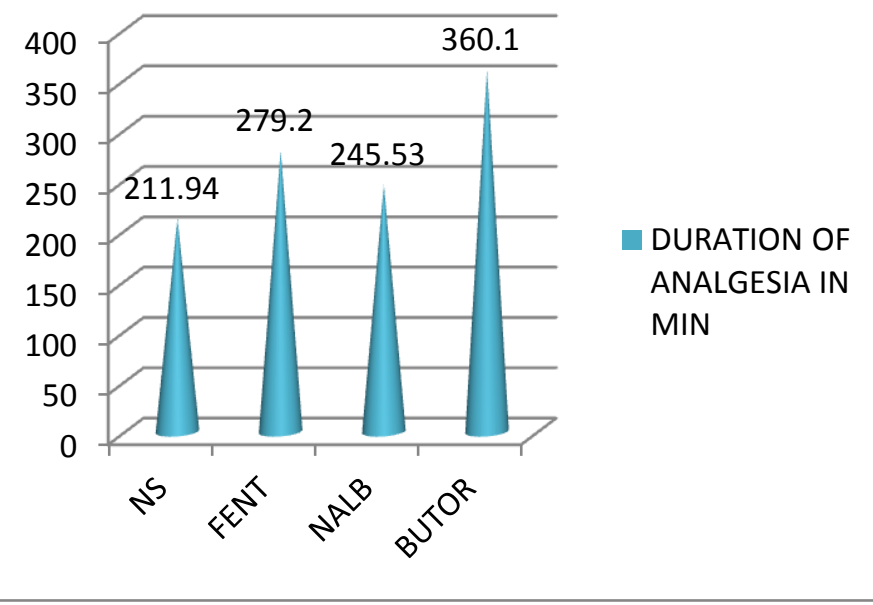

Fig-7

Satisfaction with the pain relief given was assessed by

1. Ability for independent side to side movement

2. VAS for satisfaction.

It was observed that, mothers of Butorphanol group was able to turn side to side for feeding their babies, instead of the surgical trauma, better than nalbuphine group, fentanyl group \& control group in the descending order. It was also observed that satisfaction was more with Butorphanol group followed by Nalbuphine group, Fentanyl group \& by control group in the descending order.

Table - 2

\begin{tabular}{|l|c|c|c|c|}
\hline $\begin{array}{l}\text { Parameter } \\
(\mathbf{m i n})\end{array}$ & $\begin{array}{c}\text { Group } \\
\text { NS } \\
(\mathbf{n = 1 8})\end{array}$ & $\begin{array}{l}\text { Group } \\
\text { FENT } \\
(\mathbf{n = 2 0})\end{array}$ & $\begin{array}{c}\text { Group } \\
\text { NALB } \\
(\mathbf{n = 1 9 )}\end{array}$ & $\begin{array}{c}\text { Group } \\
\text { BUTOR } \\
(\mathbf{n = 1 9 )}\end{array}$ \\
\hline $\begin{array}{l}\text { Independent } \\
\text { Change of } \\
\text { position }\end{array}$ & $22 \%$ & $30 \%$ & $42 \%$ & $84 \%$ \\
\hline $\begin{array}{l}\text { VAS for } \\
\text { Satisfaction }\end{array}$ & 4.33 & 5.45 & 6.42 & 7.11 \\
\hline
\end{tabular}

There were no motor blockade observed in any of the study groups (Bromage score was Grade I). Nausea \& Vomiting was observed in both control group (incidence of 6\%) \& fentanyl group (incidence of 20\%)

Pruritus was observed only in the fentanyl group with a incidence of $15 \%$. Sedation was observed in all the groups (Control - 17\%, Fentanyl - 25\%, Nalbuphine - 58\%, Butorphanol - $63 \%$. Butorphanol \& Nalbuphine groups had more incidence of sedation \& higher grades of sedation 
(Grade 4). None of the patients developed hypotension, Bradycardia, respiratory depression.

\section{Discussion}

The analgesic efficacy \& side effects of Epidural $0.125 \%$ Bupivacaine + Normal saline; $0.125 \%$ Bupivacaine + fentanyl 50ug; 0.125\% Bupivacaine + Nalbuphine 5mg \& $0.125 \%$ Bupivacaine + Butorphanol $1 \mathrm{mg}$ were studied.

1.The onset of analgesia was earlier \& the duration of analgesia was prolonged in all the opioid groups when compared to the control group. The study has once again confirmed that combination of an opioid and a local anesthetic enhances the onset and prolongs the duration of analgesia more than the local anesthetic alone.

Results of our study correlate with study done by Abboud and coworkers who found significantly better quality of analgesia in parturients receiving epidural bupivacaine with butorphanol than with bupivacaine alone $^{(\mathbf{1})}$, (epidural LA with opioid better than LA alone)

Shrestha et al, in his study has shown that $2 \mathrm{mg}$ of epidural butorphanol added to a lower concentration of bupivacaine $(0.1 \%)$ provided a better quality of labor analgesia than $0.25 \%$ bupivacaine alone. ${ }^{(2)}$ (epidural LA with opioid better than LA alone) which again correlate with our study.

2. Butorphanol in addition to bupivacaine produce earlier onset and longer duration of analgesia than Nalbuphine \& Fentanyl in epidural analgesia. Epidural Butorphanol with bupivacaine also had better patient satisfaction in terms of VAS for Satisfaction and ability for independent movement (position change).

Pokharel $\mathrm{K}$ et al in his study, Low dose $(0.5 \mathrm{mg})$ of epidural butorphanol with bupivacaine $0.125 \%$ was studied in parturients following cesarean delivery. Parturients were allocated into two groups: group 1 received epidural $0.125 \%$ bupivacaine while group 2 received an additional of $0.5 \mathrm{mg}$ butorphanol $^{(\mathbf{3})}$. The epidural route was used for postoperative analgesia with the study drug. The onset and duration of analgesia in group $2(4.1+/-2.6 \mathrm{~min}$ and 202.4+/-62.8 $\mathrm{min}$ ) were significantly different
$(\mathrm{P}<0.01)$ from group $1(6.6+/-2.7 \mathrm{~min}$ and $145.7+/-$ $89.6 \mathrm{~min}$ ). Results we obtained were (Butorphanol group - onset of analgesia was $3.42 \mathrm{~min}$, duration of analgesia was $360 \mathrm{~min} \& \mathrm{NS}$ group - onset of analgesia was $8.22 \mathrm{~min}$, duration of analgesia was $211 \mathrm{~min}$ ). Both the results are comparable, except for an early onset of analgesia \& prolonged duration of analgesia we obtained in our study, which could probably attributed to a little higher dose (1mg of butorphanol) used in our study.

Gupta $R$ et al in his study on Post operative analgesia in patients undergoing lower limb surgery with $2 \mathrm{mg}$ butorphanol as bolus epidurally diluted in $10 \mathrm{ml}$ normal saline, found the duration of analgesia to be $5.35 \pm 0.29 \mathrm{hrs}$. The duration of analgesia in this study was comparable to our study (duration = $360 \mathrm{~min}){ }^{(4)}$

3. Nalbuphine in combination with bupivacaine produced delay onset \& shorter duration of analgesia when compared to Fentanyl \& Butorphanol groups, but definitely earlier onset and longer duration of analgesia than bupivacaine alone. Though the onset of analgesia was delayed and duration of analgesia was short in the Nalbuphine group when compared to the fentanyl group, patient satisfaction was better in the Nalbuphine group, probably because the side effects like nausea/ vomiting; pruritus are less with Nalbuphine compared to Fentanyl.

Baxter $A D$ et al in his study, demonstrated that after cesarean delivery with epidural lidocaine, epidural Nalbuphine in doses of 10,20, and $30 \mathrm{mg}$ promoted satisfactory analgesia, but with a duration of only $1-3 h^{(5)}$

Pugh GC et $a l^{(\mathbf{6})}$, in his study mentioned nalbuphine as an analgesic agent provides a number of advantages. Used as the sole opioid analgesic, it can satisfactorily cover mild to moderate pain with a low incidence of side effects. The ceiling effect of nalbuphine, which prevents it from supplying sufficient analgesia to cover the most severe discomfort, also prevents increasing sedation and respiratory depression as the dose is increased, potentially providing an increased safety margin in comparison to mu-agonists. When nalbuphine is 
used concurrently with mu-agonists (e.g. morphine, fentanyl) the benefits of both mu- and kappaanalgesia can be obtained, with simultaneously decreased incidence and severity of the common mu-agonist side effects (pruritis, nausea/emesis, constipation, urinary retention, respiratory depression and undesirable sedation).

4. Though the incidence of sedation is more in Butorphanol \& Nalbuphine groups, all the patients were easily arousable. butorphanol is associated with profound dose-dependent sedation with reported somnolence in more than $50 \%$ of patients at doses $2 \mathrm{mg}$ or more. ${ }^{(7)}$

In our study we have used only $1 \mathrm{mg}$ epidurally, hence the sedation cannot be fully attributed to the drug. The contribution of factors such as sleep deprivation, exhaustion and anxiety during surgery renders the patients drowsy or sleepy cannot be denied

5.In the study, we did not observe nausea and vomiting in Butorphanol \& Nalbuphine groups. Fentanyl group had nausea \& vomiting upto $20 \%$ more than control group $(5.55 \%)$

Cohen et al in his study for postcesarean analgesia, found epidural bupivacaine when combined fentanyl had more more nausea and vomiting than bupivacaine alone ${ }^{(\mathbf{8})}$ which correlates with our study. 6. In the study, we did not observe pruritus in Butorphanol \& Nalbuphine groups which could be compared with the following studies;

$J$ S Naulty et al in his study on epidural Butorphanol after delivery of baby $1 \mathrm{mg}, 2 \mathrm{mg}, 4 \mathrm{mg}$ in 40 parturients, results showed increasing duration of analgesia as dose increases, but no statistical significance. No case reported pruritus. somnolence. Prophylactic administration of butorphanol has been recommended for prevention of such side effects produced by pure agonist opioids like morphine and it has also been effectively used for the treatment of intractable pruritis associated with dermatological conditions $^{(\mathbf{9})}$

Wittles et al found that epidural nalbuphine $10 \mathrm{mg}$ reduced the incidence of pruritus from $48 \%$ to $20 \%$ for $6 \mathrm{~h}^{(\mathbf{1 0})}$

\section{Conclusion}

Epidural $0.125 \%$ Bupivacaine combined with Butorphanol produces significantly earlier onset, longer duration and better quality of analgesia than $0.125 \%$ Bupivacaine - Nalbuphine combination / $0.125 \%$ Bupivacaine -Fentanyl combination / 0.125\% Bupivacaine alone and is safe in parturients.

\section{References}

1. Abboud TK, Afrasiabi A, Zhu J, Mantilla M, Reyes A, D'Onofrio L, et al. Epidural morphine or butorphanol augments bupivacaine analgesia during labor. Reg Anesth 1989;14:115-20.

2. Shrestha CK, Sharma KR, Shrestha RR. Comparative study of epidural administration of $10 \mathrm{ml}$ of $0.1 \%$ bupivacaine with $2 \mathrm{mg}$ butorphanol and $10 \mathrm{ml}$ of $0.25 \%$ plain bupivacaine for analgesia during labor. J Nepal Med Assoc 2007;46:1-6.

3. Pokharel K, Rahman TR, Singh SN, Bhattarai B, Basnet N, Khaniya S.et al; JNMA J Nepal Med Assoc. 2008 AprJun;47(170):57-61.

4. Gupta R, Kaur S, Singh S, Aujla KS. A comparison of epidural butorphanol and tramadol for postoperative analgesia using CSEA technique. J Anaesthesiol Clin Pharmacol 2011;27:35-8

5. Baxter AD, Laganiere S, Samson B, et al. A dose-response study of nalbuphine for postthoracotomy epidural analgesia. Can $\mathbf{J}$ Anaesth 1991.

6. Pugh GC, Drummond GB. A dose-response study with nalbuphine hydrochloride for pain in patients after upper abdominal surgery. Br J Anaesth 1987;59:1356-63.

7. Hunt co, datta s, ostheimer gw. Epidural butorphanol-bupivacaine for analgesia during labor and delivery. Anesth Analg 1989;68:323-7.

8. Cohen SE, Subak LL, Brose WG, Halpern J. Analgesia after cesarean delivery: patient evaluations and costs of five opioid techniques.Reg Anesth 1991;16:141-9. 
9. Naulty JS, Weintraub S, Mcmahon J, Ostheimer GW, Hunt C, Chantigian R. Epidural butorphanol for post cesarean delivery pain management. Anesthesiology 1984;61:A415.

10. Wittels B, Glosten B, Faure EA, Moawad AH, Ismail M, Hibbard J, et al. Opioid antagonist adjuncts to epidural morphine for postcesarean analgesia: Maternal outcomes. Anesth Analg 1993;77:925-32. 